
информационном пространстве: современные кадры забота самих библиотек

Реферат. Основная задача настоящей публикации - показать подход к решению вопроса повышения профессионального уровня библиотечных специалистов в условиях внедрения новых информационно-коммуникационных технологий (ИКТ) и развития рынка электронных продуктов и услуг. Отмечено, что базовое профессиональное образование не вполне соответствует вызовам формирующегося электронного библиотечно-информационного пространства. Поэтому библиотеки ищут свои подходы к повышению профессионального уровня сотрудников и обслуживаемой среды. Рассмотрен опыт Библиотеки по естественным наукам Российской академии наук (БЕН РАН), ориентированный на семинарские и практические (тренинги) занятия. Основное внимание уделяется следующим направлениям: освоение правил и приобретение навыков работы с библиометрическими и специализированными базами данных; работа с ресурсами открытого доступа (Open Access); состояние рынка электронных продуктов и услуг и условия доступа к ним. Показано, что подобный подход интересен не только библиотечным специалистам, но и ученым научно-исследовательских институтов, которые заинтересованы в развитии информационной грамотности. Приведены темы конкретных занятий.

Ключевые слова: библиотека, БЕН РАН, повышение квалификации, ИКТ, непрерывное обучение.

Для цитирования: Каленов H.E., Цветкова В.A. Новые вызовы в библиотечно-информационном пространстве: современные кадры - забота самих библиотек // Библиотековедение. 2017. Т. 66 , № 5. C. 587-591. DOI: 10.25281/0869-608X-201766-5-587-591.

Д ля современного периода развития библиотечного мира характерна некая двойственность. С одной стороны, библиотеки остаются хранителями накопленных знаний в форме традиционных книг, журналов и прочих изданий, т. е. классическая библиотечная функция не отмирает, а продолжает жить и адаптироваться к вызовам нового времени. С другой стороны, стремительное развитие и проникновение в библиотечную практику новых информационных технологий, включая электронные каталоги, электронную доставку документов, электронные издания, базы и банки данных, требуют от библиотек развертывания принципиально новых методов работы. Противостоять этим непро-

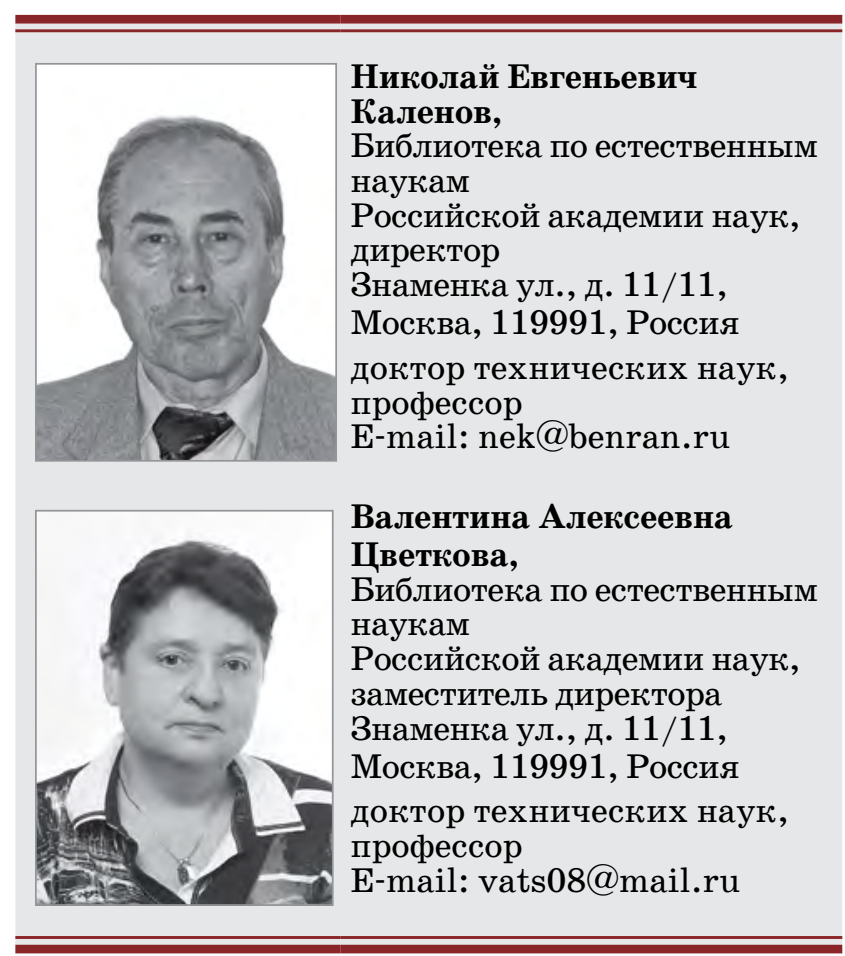


стым вызовам смогут только те структуры, которые имеют кадровый потенциал, способный работать как с традиционными ресурсами, так и с электронными сервисами, развивающимися в мировом информационном пространстве. Эти процессы характерны как для российских, так и для зарубежных библиотечно-информационных структур [1].

Смогут ли научные библиотеки достойно ответить на вызовы нового времени, во многом определяется профессиональной подготовкой их кадров. Именно эта задача становится в ряд первоочередных в решении вопросов по организации современного информационного обеспечения ученых и специалистов.

Надо отметить, что обучение библиотечной работе на современном профессиональном уровне не в полной мере отвечает высоким требованиям развития информационных технологий. Вузовское образование в значительной степени направлено на традиционные дисциплины. $\kappa$ сожалению, прием на библиотечно-информационные факультеты сокращается, да и молодежь не очень охотно идет обучаться библиотечному делу, считая его консервативным, несовременным [2]. Изменить ситуацию можно будет лишь в том случае, если библиотечное дело вернет свой престиж, изменит парадигму позиционирования на площадке современных технологий [3]. Именно библиотекам выпала честь быть на самом острие информационно-коммуникационных технологий (ИКТ). Именно они должны решать вопросы по организации информационного обслуживания на базе электронных ресурсов; уметь работать с разнотипными базами данных, включая цитатные, с электронными библиотеками; оперативно, с учетом особенностей тематических направлений, использовать ресурсы открытого доступа; развивать новые сервисы на основе стремительно развивающихся ИКТ. Специалист из Великобритании Д. Хейе отмечает, что библиотечно-информационные профессионалы должны «непрерывно учиться, активно накапливать опыт, позитивно воспринимать перемены, отмечая в них светлые стороны, учиться всему новому, адаптироваться к электронной среде в соответствии с ее переменами» [4].

Наряду с проблемами базового библиотечного образования, у нас, к сожалению, отсутствует целостная система переподготовки библиотечных кадров. Несколько лет назад в стране было три структуры, имевшие право выдавать дипломы государственного образца по этой форме образования: Академия переподготовки работников искусства, культуры и туризма (АПРИКТ), Учебный центр послевузовского и дополнительного профессионального образования специалистов Российской государственной библиотеки, Омский региональный инновационный центр. Кроме того, существовал Институт повышения квалификации информационных работников (ИПКИР). В 2017 г. выполняют свои функции Учебный центр Российской государственной библиотеки и Омский региональный инновационный центр. Образовательные функции АПРИКТа переданы в Московский государственный институт культуры (МГИК), но, по-настоящему, курсы при МГИКе пока работать не начали, ИПКИР закрыт.

В этих условиях библиотеки должны сами искать пути подбора кадров и повышения их профессиональной квалификации. Данный процесс должен быть постоянным. Осуществляться он может по следующим моделям:

- в специальных институтах повышения квалификации, которых в стране практически не осталось;

- на рабочем месте путем индивидуального самообразования и обмена опытом с коллегами;

- путем организации специальных занятий: семинаров, тренингов по актуальным проблемам в рамках библиотеки, проводимых как приглашенными специалистами, так и наиболее квалифицированными сотрудниками самой библиотеки.

Безусловно, развивается и система самообразования, захватывая наиболее способных и готовых к восприятию сотрудников. Нельзя не отметить, что вопросы самообразования не являются новыми. Известный библиограф-просветитель Н.А. Рубакин отмечал важность постоянного самообразования. Им был разработан целый ряд программ для самообразования, актуальных для его времени [5]. Его слова «самообразование характерное явление наших дней, это знамение нашего времени» актуальны, как никогда. Однако отметим, что сегодня профессиональных программ для самообразования не разработано, хотя очевидно, что назрела необходимость восстановления этой формы обучения. Специалистов, способных подготовить программы и пособия для самообразования, надлежит выделять и поощрять.

В последнее время перед Библиотекой по естественным наукам Российской академии наук (БЕН РАН), являющейся одним из ведущих центров информационного сопровождения фундаментальных научных исследований, достаточно остро встали вопросы обучения персонала современным методам информационной работы, основанным на широком использовании возможностей сетевых технологий и ресурсов, представленных в Интернете.

Проанализировав существующие структуры по организации профессиональной переподготовки и повышения квалификации библиотечных специалистов, пришли к выводу, что «спасение утопающих - дело рук самих утопающих». Было принято решение проводить обучение сотрудников в форме семинарских занятий. Учитывая, что возможности для материального поощрения квалифицированных специалистов БЕН РАН практически не имеет и государственным зада- 
нием обучение не предусмотрено, для проведения ознакомительных теоретических и практических занятий были привлечены собственные сотрудники и специалисты из других организаций на условиях волонтерства или обмена опытом.

В БЕН РАН вопрос профессиональной переподготовки затрагивает не только кадровый состав самой Центральной библиотеки и ее отделов в научно-исследовательских институтах (НИИ). Вопрос современной информационной грамотности важен и для сотрудников этих институтов, поскольку при проведении исследований им приходится подбирать необходимые материалы, корректно оформлять ссылки на используемые источники (для дальнейшего их отражения в БД цитирования), занимать «свое место» в научном информационном пространстве. Они должны уметь самостоятельно работать с информационными и библиометрическими базами данных, искать специфическую информацию при проведении исследований, оценивать свою публикационную активность. Безусловно, основную часть информации они получают от библиотечных структур, но владеть навыками поиска, знать, какие информационные ресурсы соответствуют темам их научных исследований, необходимо и престижно для самих ученых.

Поэтому идея образовательных семинаров БЕН РАН вызвала живой интерес и активное участие, в частности, специалистов, занятых исследованиями в области химии и химических технологий. Постепенно информация о семинарах в БЕН РАН стала известна более широкой аудитории. В результате нашими слушателями стали сотрудники Всероссийской патентно-технической библиотеки Федеральной информационной патентной службы (ВПТБ ФИПС), Российской государственной библиотеки (РГБ), Всероссийского института научной и технической информации (ВИНИТИ) РАН, Центральной научной сельскохозяйственной библиотеки (ЦНСХБ), медицинских библиотек и др.

В условиях стремительно меняющихся информационных технологий без постоянного обучения и переподготовки специалистов просто невозможно работать. $К$ сожалению, руководящие организации не только не учитывают процессы переподготовки специалистов в плановых и отчетных документах, но и не выделяют материальных ресурсов даже на проведение научных семинаров. В частности, в 2017 г. (впервые за 32 года) не был профинансирован семинар «Информационное обеспечение науки: новые технологии», организуемый БЕН РАН один раз в два года. Ранее это мероприятие поддерживали Российская академия наук и Российский фонд фундаментальных исследований (РФФИ). В 2017 г. и Федеральное агентство научных организаций (ФАНО) России (в структуру которого была передана Библиотека после реорганизации РАН), и РФФИ в его финансировании отказали.
Стартовым в направлении переподготовки кадров БЕН РАН явился 2015 год. Основными ее предпосылками стали:

- необходимость работы с многочисленными базами данных, к которым предоставляется доступ в рамках национальной подписки (в том числе проведения библиометрических исследований в интересах обслуживаемых академических организаций);

- потребности в использовании ресурсов открытого доступа (Open Access) для информационного обеспечения тематических научных направлений;

- необходимость умения ориентироваться в постоянно расширяющемся научном пространстве, выявляя новые информационные ресурсы и информируя ученых о них.

В качестве основных форм обучения сотрудников были организованы семинары, проводимые квалифицированными специалистами собственно Библиотеки; семинары, проводимые приглашенными специалистами; ознакомление с опытом работы информационных, библиотечных и архивных структур.

Одними из основных мероприятий по повышению квалификации сотрудников БЕН РАН, начиная с 2015 г., являются семинары по работе с базой данных Web of Science (WOS) Core Collection, проводимые специалистами компании “Thomson Reuters" (с января 2017 г. — “Clarivate Analitics”). За прошедшее время были осуществлены обучающие семинары на площадке БЕН PAH, а также лицензионные семинары на площадке фирмы. Пять специалистов получили дипломы с правом вести занятия внутри организации. Часть сотрудников приняли участие в онлайн-семинарах, которые фирма проводит на русском языке бесплатно. Необходимо отметить дружелюбность специалистов компании и их желание повысить профессиональный уровень библиотекарей, работающих с этим ресурсом.

Были организованы также семинары по базе данных Scopus, которая вместе c WOS занимает лидирующее положение в мире как наиболее крупная политематическая реферативная база данных и основа для проведения библиометрических исследований. Семинары проводили специалисты издательства Elsevier - производителя и поставщика данной базы.

Обучение работе с базой данных «Российский индекс научного цитирования» (РИНЦ) было проведено наиболее опытными специалистами Библиотеки. Основатель РИНЦа - Научная электронная библиотека eLIBRARY.RU - проводит такие занятия постоянно, но на платной основе. Поскольку имеются жесткие ограничения по финансированию, воспользоваться этой услугой Библиотека не может. Самостоятельное освоение позволило глубоко изучить систему и провести оценку ее возможностей [6-9]. 
Наряду с семинарами по работе с базами данных цитирования, БЕН РАН организовала серию семинаров по ознакомлению с полиграфической продукцией и политикой ведущих зарубежных издательств, а также по особенностям работы с проблемно-ориентированными базами данных. В числе таких семинаров можно назвать:

- Электронные научные ресурсы издательства Hanser: библиотечно-информационные и издательские технологии. Семинар провели Д. Хиндерланг (D. Hinderlang), коммерческий директор издательства Carl Hanser Verlag GmbH \& Co. KG (Германия) и И. Бергер (Y. Berger), управляющий директор агентства Karger Libri (Швейцария);

- Инновационный проект издательства Karger по продвижению российских авторов. Семинар провели Г. Каргер (G. Karger), президент издательской компании Karger Publishers (Швейцария), М. Томмэн (М. Thommen), коммерческий директор Karger Publishers (Швейцария) и О.В. Тимофеева, коммерческий директор компании «Мир Периодики» (Россия), представителя Karger Publishers в нашей стране;

- Обучающий семинар по работе с информационно-поисковой системой химической информации SciFinder, который провел В.-П. Хёттинен (V.-P. Hyttinen), региональный представитель ACS (American Chemical Society);

- Информационные решения Elsevier. Семинар провел А.Г. Худошин, директор направления химико-биологических решений Elsevier S\&T в России, Иране и странах СНГ;

- Эффективное использование ресурсов SPRINGER NATURE в повседневной работе. Cеминар провела Д.М. Иовчева, руководитель отдела продаж и клиентских отношений.

Учитывая, что БЕН РАН ведет обслуживание специалистов по разным тематическим направлениям, проблематику семинаров планируется расширить, распространив их на проблемно-ориентированные базы данных (например, MathNET по математике, Reaxys по химии, BIOSIS по биологии и т. п.).

Интерес к занятиям, проводимым в Библиотеке, возрастает. Участие в них принимают специалисты не только из институтов, включенных в сферу БЕН РАН, но и из организаций других ведомств.

В заключение отметим еще раз, что вызовы настоящего времени требуют соответствующих квалифицированных специалистов, а это задача самих библиотечно-информационных структур. Безусловно, на государственном уровне должно возродиться понимание важности этого направления, что повлечет за собой и развитие системы подготовки и переподготовки кадрового состава в режиме постоянного обучения.

Хочется выразить признательность нашим постоянным партнерам, без которых вряд ли бы удалось организовать подобное обучение:
В.В. Богорову, представителю компании "Clarivate Analitics" в России;

К.Н. Костюку, генеральному директору электронного издательства ООО «Директ медиа Паблишинг»;

О.В. Тимофеевой, коммерческому директору ООО «Мир Периодики»;

Е.А. Ерониной, представителю "ProQuest" в России;

Т.А. Елистратовой, консультанту по академической литературе, Представительство Издательства Кембриджского университета в Москве (до 2017 года).

Детальная информация о проведенных семинарах (программы, ведущие, материалы) представлена в специальном разделе сайта БЕН РАН (http://benran.ru).

\section{Список источников}

1. Библиотечно-информационная профессия за рубежом: современное состояние, проблемы, перспективы (обзор по материалам отечественной и зарубежной англоязычной литературы 2006-2008 гг.) [Электронный pecypc]. URL: ifapcom.ru/files/ Monitoring/2009/bagrova_bib_inf_prof.pdf (дата обращения: 19.08.2017).

2. Мазурицкий А.М. Кризис библиотечно-информационного образования. Правда или вымысел? [Электронный ресурс]. URL: gpntb.ru/win/interEvents/cremia2011/disk/126.pdf (дата обращения: 07.08.2017).

3. Захаренко М.П. Привлекательность библиотечной профессии для молодежи: опыт социологического исследования [Электронный ресурс]. URL: http:// www.rsl.ru/ru/s3/s17/s33/bv32010/bv320105398 (дата обращения: 07.09.2017).

4. Heye D. Characteristics of the successful twenty-first century information professional. Oxford : Chandos Publishing, 2006. $167 \mathrm{p}$.

5. Рубакин Н.А. Избранное : в 2 т. Москва : Книга, 1975. T. 1. C. $126,139$.

6. Цветкова В.А. Система цитирования: где благо, где зло // Научные и технические библиотеки. 2015. № 1. C. $18-22$.

7. Мохначева Ю.В., Цветкова В.А. О публикационных потоках медико-биологического профиля на примере НИИ Федерального агентства научных организаций России // Информация и инновации. 2017. № 1-2. C. $61-69$.

8. Цветкова В.А., Калашникова Г.В. Еще немного о Российском индексе научного цитирования (РИНЦ) [Электронный ресурс] // Культура: теория и практика: [электронный научный журнал МГИК]. 2016. Выпуск 5-6 (14-15) URL: http://theoryofculture. $\mathrm{ru} / \mathrm{issues} / 69 / 891$ / (дата обращения: 08.09.2017).

9. Каленов Н.Е., Селюикая О.В. О российском индексе цитирования // Новые технологии в информационно-библиотечном обеспечении научных исследований : сб. науч. тр. Екатеринбург : Уральский центр академического обслуживания, 2010. C. $200-217$. 


\title{
The New Challenges in the Library- Information Space: Contemporary Staff is the Responsibility of Library Itself
}

\author{
Nikolay E. Kalenov*, Valentina A. Tsvetkova** \\ Library for Natural Sciences of the Russian Academy of Sciences, 11/11 Znamenka Str., Moscow, 119991, \\ Russia \\ E-mail:*nek@benran.ru ,**vats08@mail.ru
}

\begin{abstract}
The main objective of the publication is to show the approach to addressing the issue of increasing the professional level of librarians in the context of implementation of new information and communication technologies (ICT) and development of the market of electronic products and services. It is noted that basic education does not fully meet the challenges of the emerging electronic library-information environment. Therefore, libraries are looking for their own approaches to improving professional level of employees and service environment. There is considered the experience of the Library for Natural Sciences of the Russian Academy of Sciences (LNS RAS), concentrated on seminars/workshops and practical training classes. The main attention is paid to the following areas: mastering of rules and development of skills in the work with bibliometric and specialized databases, work with the resources of Open Access, condition of the market of electronic products and services, and the terms of access to them. It is shown that this approach is topical not only to library professionals, but also to the scientists of research institutes who are interested in the development of information literacy. There are presented the topics of particular trainings.
\end{abstract}

Key words: Library, Library for Natural Sciences of the Russian Academy of Sciences, Advanced Training, Information and Communication Technologies, Continuous Learning.

Citation: Kalenov N.E., Tsvetkova V.A. The New Challenges in the Library-Information Space: Contemporary Staff is the Responsibility of Library Itself, Bibliotekovedenie [Librari and Information Science], 2017, vol. 66, no. 5, pp. 587-591. DOI: 10.25281/0869-608X-2017-66-5-587-591.

\section{References}

1. Bibliotechno-informatsionnaya professiya za rubezhom: sovremennoe sostoyanie, problemy, perspektivy (obzor po materialam otechestvennoi $i$ zarubezhnoi angloyazychnoi literatury 2006-2008 gg.) [The Library and Information Profession Abroad: The Current State, Problems, Prospects (A Review on the Materials of Russian and Foreign English-Language Literature of 2006-2008)]. Available at: ifapcom. $\mathrm{ru} /$ files/Monitoring/2009/bagrova_bib_inf_prof.pdf (accessed 19.08.2017).

2. Mazuritsky A.M. Krizis bibliotechno-informatsionnogo obrazovaniya. Pravda ili vymysel? [Crisis of Library Information Education. Is It Real?]. Available at: http://www.gpntb.ru/win/Inter-Events/ crimea2011/disk/126.pdf (accessed 07.08.2017).

3. Zakharenko M.P. Privlekatel'nost' bibliotechnoi professii dlya molodezhi: opyt sotsiologicheskogo issledovaniya [The Attractiveness of the Library Profession for Young People: The Experience of Sociological Survey]. Available at: http://www.rsl.ru/ru/s3/s17/ s33/bv32010/bv320105398 (accessed 07.09.2017).

4. Heye D. Characteristics of the successful twenty-first century information professional. Oxford, Shandos Publishing, 2006, $167 \mathrm{p}$.

5. Rubakin N.A. Izbrannoe: $v 2 t$. [Selected Works: in 2 volumes]. Moscow, Kniga Publ., 1975, vol. 1, pp. 126, 139.
6. Tsvetkova V.A. Sistema tsitirovaniya: gde blago, gde zlo [Citation Systems: Which Is Good, and Which Is Evil], Nauchnye i tekhnicheskie biblioteki [Scientific and Technical Libraries], 2015, no. 1, pp. 18-22.

7. Mokhnacheva Yu.V., Tsvetkova V.A. O publikatsionnykh potokakh mediko-biologicheskogo profilya na primere NII Federal'nogo agentstva nauchnykh organizatsii Rossii [About Medical and Biological Publication Flows by the Example of the Federal Agency of Scientific Organizations of Russia], Informatsiya i innovatsii [Information and Innovations], 2017, no. 1-2, pp. 61-69.

8. Tsvetkova V.A., Kalashnikova G.V. Eshche nemnogo o Rossiiskom indekse nauchnogo tsitirovaniya (RINTs) [A Little More about the Russian Science Citation Index (RSCI)], Kul'tura: teoriya i praktika [Culture: Theory and Practice], 2016, issue 5-6 (14-15). Available at: http://theoryofculture.ru/ issues/69/891/ (accessed 08.09.2017).

9. Kalenov N.E., Selyutskaya O.V. O rossiiskom indekse tsitirovaniya [On the Russian Citation Index], Novye tekhnologii $v$ informatsionno-bibliotechnom obespechenii nauchnykh issledovanii: sb. nauch. tr. [New Technologies in the Information and Library Support of Scientific Research: collection of scientific papers]. Yekaterinburg, Ural'skii Tsentr Akademicheskogo Obsluzhivaniya Publ., 2010, pp. 200-217. 